\title{
Examination of Inequality of Life Span by Using the Gini Coefficient in the Turkish Population for the Period 1990-2008
}

\author{
Pınar Özdemir ${ }^{1}$, Erdem Karabulut ${ }^{1}$, Turhan Menteş ${ }^{2}$ \\ 'Department of Biostatistics, Faculty of Medicine, Hacettepe University, Ankara, Turkey \\ ${ }^{2}$ Department of Statistics, Science of Medicine, Hacettepe University, Ankara, Turkey
}

\section{ABSTRACT}

Objective: The aim of this study is to show that the Gini coefficient used in economics, particularly in exposing inequality in income levels can also be used in the field of health, especially for measuring inequality specific to any issue of concern. Based on life tables, this study uses the Gini coefficient in measuring the extent of inequality in years lived and shows the level of these inequalities in Turkey for the period $1990-2008$.

Material and Methods: Lorenz Curves were constructed by using data from life tables pertaining to years $1990,2000,2006$ and 2008 as given by WHO database, Gini coefficients were calculated in measuring variability in length of life expectancies in general, for the male and female population and then used in examining reducing inequality over time.

Results: Taking 1990 as the base year, life expectancy at birth has increased by 9.3 years by 2008 and inequality has decreased from 0.188 to 0.114 (by $39 \%)$ in the same period.

Conclusion: In addition to the target of increasing life expectancy, the assessment of success in ensuring all individuals live up to average life expectancy should be conducted by using this measure of inequality.

Key Words: Gini coefficient, Lorenz Curve, life table, inequality measure

Received: 13.09 .2010

Accepted: $24 \cdot 10.2010$

\section{Introduction}

Average life expectancy at birth $\left(e_{0}\right)$ is one of the most important indicators of a country's level of development in health. Today, life expectancy at birth is quite high in some countries while it is alarmingly low in some others. According to life tables of 193 countries given in the website of the World Health Organization (World Health Organization Life Table Database) the highest life expectancies at birth for the year 2008 are seen in San Marino (82.9 years) and Japan (82.8 years) (1). As for males, life expectancy at birth is 81.3 years in San Marino ( $1^{\text {st }}$ among 193 countries) and 79.4 years in Japan ( $5^{\text {th }}$ among 193 countries). For females, life expectancy at birth is 86.1 years in Japan ( $1^{\text {st }}$ among 193 countries) and 84.5 years in San Marino ( $5^{\text {th }}$ among 193 countries) (1). Again according to the 2008 WHO data, the lowest life expectancy is 41.9 years in Afghanistan (1). As for Turkey, she ranks $57^{\text {th }}$ with average life expectancy of 74.3 years. In gender terms, Turkey ranks $59^{\text {th }}$ in males with life expectancy of 71.7 years and $61^{\text {st }}$ in females with life expectancy of 77.0 years.

It is beyond doubt that one of the most desirable targets for any country in the field of health is to maximize life expectancy at birth. In measuring this, it is sufficient to calculate life expectancy at birth $\left(e_{0}\right)$. Measuring whether people in a given society reach as close as possible to the expected years in life, in other words having information about how large or small deviations from average life expectancy are will of course be useful in assessing and improving health policies.

Equal access to and enjoyment of health services by all is a desirable situation which has not yet been attained. There would have been no discussion about inequality if that target could have been attained. In fact, however, given an average life expectancy as 75 years, it would be an Utopian target to ensure that all live up to age 75. Nevertheless, it is still an important criterion for the level of development attained to check how close individuals get to that age.

So far, many health indicators have been developed to pinpoint the level of health attained, track changes taking place in time, compare countries with respect to their health indicators and to develop appropriate health policies. However, these are average indicators such as infant mortality rate and life expectancy.

Compared to a country with high life expectancy at birth, does a country with lower life expectancy also face wider variance and inequality in life expectancy of its citizens? Or given two countries having equal life expectancies, do these countries also display similar variability and inequality in length of life? As a result of questions like these, measures of variation in the context of the concept of life expectancy draw 
more and more attention. Consequently, various measures have been developed for the dispersion in the distribution of length of life. These measures seek to explain the level of inequality or variability through different ways. Some take the Lorenz curve as a basis. Among these, the most widely known and frequently used is the Gini coefficient.

There are few studies on how indicators relating to level of health in a given society vary in time. In Turkey, other than economic indicators, health indicators exposing the overall state of society are given as averages, and there are very few studies on how these indicators vary within society. Özdemir and Karabulut examined how infant deaths varied with respect to regions and provinces (2). Shkolnikov et al. led the first study on the use of the Gini coefficient as a function of life table in measuring variability in length of life (3). Edwards RA explored patterns in life-span variance in a broad panel of 180 rich and poor countries between 1970 and 2000 (4).

It is also possible to use the Lorenz curve and Gini coefficient in different assessments in the field of health. For example, Lee suggested using the Lorenz curve and Gini coefficient as alternatives to relative risk and attributable risk measures frequently used in examining exposure-disease association (5). Lee also proposed the Lorenz curve and Gini coefficient as a new approach in assessing the performance of diagnostic tests (6).

The number of studies so far conducted to assess inequalities is quite limited. The purpose of this study is to assess inequalities in length of life in Turkey as average life expectancy is rising, show the trend that inequalities follow, and suggest the use of the method together with other indicators concerned in exposing variations in measures of inequality.

\section{Material and Method}

\section{Lorenz curve}

The Lorenz Curve is a graphical function frequently used by economists in measuring the pattern of income distribution and by demographers in measuring densities in population distribution (6). While its use in the field of health is novel, there are some important studies on this subject.

The Lorenz Curve is the curve obtained from cumulative frequencies when sub-groups are hierarchically ranked in line with increasing frequencies. When the Lorenz Curve is constructed for health related variables, the $\mathrm{x}$-axis represents cumulative percentage of population whereas the $y$-axis represents cumulative percentage of the health related variable concerned (Figure 1). A straight diagonal is the line of perfect equality while diversions from this diagonal line signify inequalities in distribution (7). Depending on the variable concerned, this curve may be above or below the diagonal line. For instance, $\mathrm{i}$ when the variable concerned is related to any social benefit, the curve will remain under the diagonal and above it otherwise.

\section{Gini coefficient}

The Gini coefficient is a summary measure of inequality, which has an easily definable relationship with the Lorenz Curve. The Gini coefficient is the proportion of the area lying between the Lorenz Curve and the diagonal (equality line) to the area under the triangle (8). In other words, the Gini coefficient is calculated as the proportional relationship of areas in the Lorenz Curve graph. Areas for calculation of the Gini Coefficient are shown in Figure 1. If the area between the equality line and the Lorenz Curve is $A$, and the area under the Lorenz Curve is $B$, the Gini coefficient is calculated as $A /(A+B)$. Hence, the Gini coefficient assumes a value in the range 0 and 1. While 0 denotes perfect equality (i.e. all have same length of life) 1 stands for perfect inequality. A Gini value under 0.20 denotes lesser, a value in the range $0.20-0.50$ medium and a value above 0.50 higher inequalities (8).

The Gini coefficient can be calculated with the aid of the Brown Formula given below:

$$
G=\left|1-\sum_{k=0}^{n-1}\left(X_{k+1}-X_{k}\right)\left(Y_{k+1}+Y_{k}\right)\right|
$$

In the Formula;

G: Gini coefficient

$X$ : Cumulative proportion of population variable

Y: Cumulative proportion of the health related variable concerned

\section{Construction of Lorenz Curve on the distribution of Life expectancy}

Instead of income and population frequently used in Lorenz Curve, inserting, respectively, the person's years lived from birth to death and cumulative number of persons dying, in other words by using data from life tables, a specific Lorenz curve can be constructed (3). On the basis of life table functions, density and distribution functions can be defined as follows:

$$
\begin{aligned}
& \mathrm{f}(\mathrm{x})=\mathrm{d}(\mathrm{x}) / \mathrm{l}(0) \\
& \mathrm{F}(\mathrm{x})=1-\mathrm{I}(\mathrm{x}) / /(0) \\
& \Phi(x)=\frac{1}{e(0) l(0)} \int_{0}^{x} t d(t) d t
\end{aligned}
$$

On the basis of the life table, the Lorenz curve can be

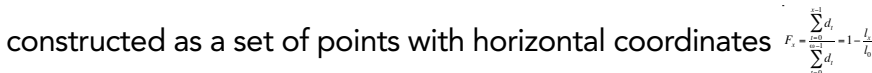

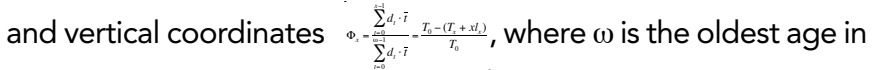
the table, $x$ runs from 0 to $\omega$, and is the average age at death of individuals dying between ages $t$ and $t+1$ (3)

$G_{0}=1-2 \int_{0}^{1} \Phi(p) d p, \mathrm{p}=\mathrm{F}(\mathrm{x})$

By using Equation 4 and Equations 1-3, Hanada (1983) obtained the following equation: (9).

$G_{0}=1-\frac{1}{e(0)[l(0)]^{2}} \int_{0}^{\infty}[l(x)]^{2} d x$ 
There are various ways of expressing the Gini coefficient as different from its geometric definition given in Equation 4 and all of these are equal to each other (3). The definition given by Kendall and Stuart will help in particular to grasp the structure of this measure (3).

$$
G_{0}=\frac{1}{2 \mu} \int_{0}^{\infty} \int_{0}^{\infty}|x-y| f(x) f(y) d(x) d(y)
$$

This equation can be taken as a Gini coefficient, simply stated, as an average of absolute differences in individual ages at death (length of life) relative to average length of life. If the population concerned consists of $I_{0}$ individuals, the Gini coefficient can be found by using the following equation: (3).

$$
G_{0}=\frac{1}{2\left(l_{0}\right)^{2} e_{0}} \sum_{i=1}^{n} \sum_{j=1}^{n}\left|x_{i}-x_{j}\right|
$$

With the functions of the standard life table, this equation can also be written as follows:

$$
G_{0}=\frac{1}{2\left(l_{0}\right)^{2} e_{0}} \sum_{x=0}^{\omega} \sum_{y=0}^{\omega} d_{x} d_{y}|\bar{x}-\bar{y}|
$$

The values and in this equation are average ages at death for the elementary age intervals $[x, x+1)$ and $[y, y+1)$, respectively.

\section{Data}

The Lorenz Curve and Gini coefficient were obtained on the basis of life tables of Turkey for the years 1990, 2000, 2006 and 2008 as given in the website of the World Health Organization "World Health Organization Life Table Database." All calculations and evaluations were made separately for the general population of the country and as well as the male and female population. In order to compare results with a country with high life expectancy, the life table of Japan for the year 1990 was used.

Statistical Softwares SAS 9.1 for Windows and Statistica 8.0 were used in drawing Lorenz Curves and calculating the Gini coefficient.

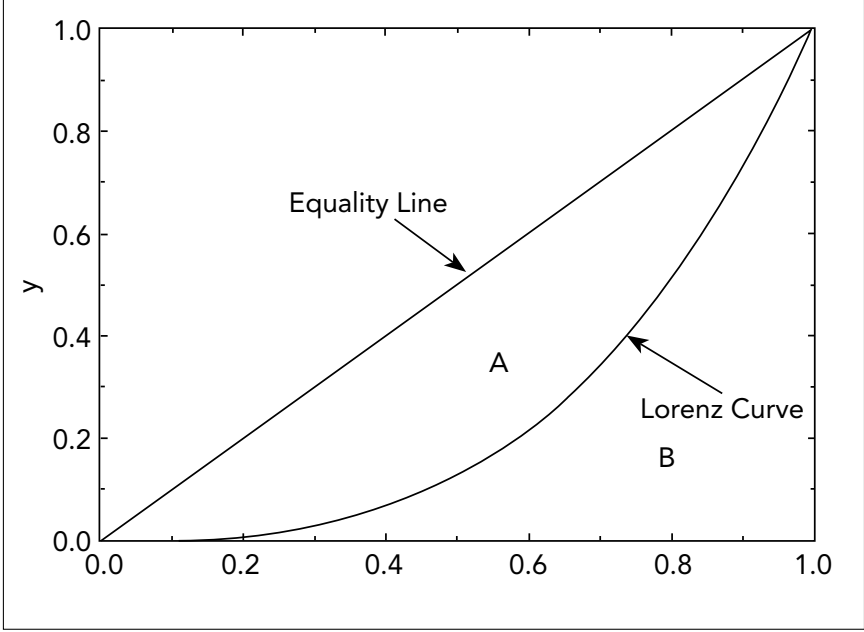

Figure 1. Lorenz Curve

\section{Results}

Inequality levels calculated for 1990, 2000, 2006 and 2008 are illustrated in Figure 2. Life expectancies at birth for these years can also be found in the same figure. Changes in Gini coefficients and expected life years at birth between 1990 and 2008 are easily seen in Figure 2. While life expectancy at birth was 65 years in 1990, it increased to 74.3 in 2008, adding 9.3 years more. In the same period, the Gini coefficient dropped from 0.188 to 0.114 . Among women, inequalities in length of life have always been lower than among males and males have life expectancies lower than females in all years. In other words, women have better chances of living up to average life expectancy than men in terms of inter-individual variability in age at death.

Table 1 gives the life table for Turkey in 2008 and coordinates of the Lorenz Curve for the same year. Figure 3 shows the Lorenz curves for the Turkish population with different average levels and age distributions of mortality in different years.

Examining the Lorenz Curve for the general population in Figure 3, we observe that all curves move towards perfect equality line in the period from 1990 to 2008. Figure 4 and 5 show the Lorenz curves for the Turkish male and female population, respectively. It is observed that in those parts where half of the population is located, curves diverge farther from each other. A similar pattern applies to both males and females and the level of disparity has fallen over the years for both males and females. The extent of inequality calculated for females is always lower than that for males. It can therefore be concluded that the female population has better chances of living up to average life expectancy than males. This also holds true for life expectancy at birth: females always have a higher life expectancy at birth compared to males.

\section{Discussion}

In a given society, one of the major aims of health services and policies is to ensure that all members of that society live in health and as long as possible. One of the crucial steps that

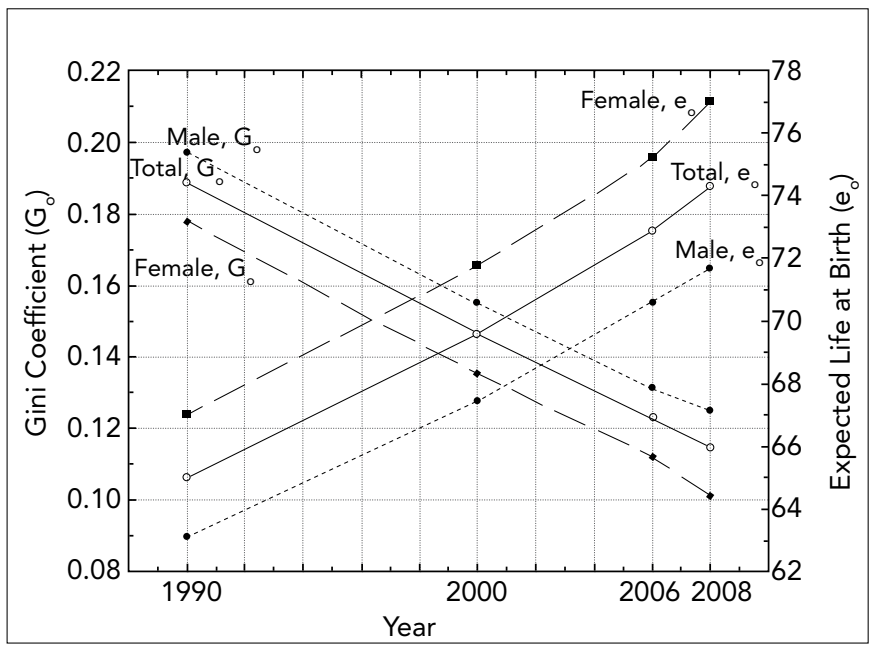

Figure 2. Changes in Gini coefficients and expected life years at birth for Turkey between 1990 and 2008 
Table 1. Life table for Turkey in 2008 and coordinates of Lorenz Curve

\begin{tabular}{|c|c|c|c|c|c|c|c|c|}
\hline \multirow[t]{2}{*}{ Age range } & \multicolumn{6}{|c|}{ Life table } & \multicolumn{2}{|c|}{ Coordinates } \\
\hline & $I_{x}$ & ${ }_{n} d_{x}$ & ${ }_{n} q_{x}$ & ${ }_{n} L_{x}$ & $T_{x}$ & $e_{x}$ & $\mathbf{x}$ & $y$ \\
\hline 0 & 100000 & 1992 & 0.0199 & 98207 & 7427572 & 74.3 & 0.000 & 0.000 \\
\hline $1-4$ & 98008 & 208 & 0.0021 & 391533 & 7329365 & 74.8 & 0.020 & 0.000 \\
\hline $5-9$ & 97800 & 169 & 0.0017 & 488577 & 6937832 & 70.9 & 0.022 & 0.000 \\
\hline $10-14$ & 97631 & 149 & 0.0015 & 487781 & 6449255 & 66.1 & 0.024 & 0.000 \\
\hline $15-19$ & 97482 & 320 & 0.0033 & 486609 & 5961474 & 61.2 & 0.025 & 0.001 \\
\hline $20-24$ & 97162 & 404 & 0.0042 & 484798 & 5474865 & 56.3 & 0.028 & 0.001 \\
\hline $25-29$ & 96758 & 400 & 0.0041 & 482788 & 4990066 & 51.6 & 0.032 & 0.002 \\
\hline $30-34$ & 96358 & 458 & 0.0047 & 480644 & 4507278 & 46.8 & 0.036 & 0.004 \\
\hline $35-39$ & 95900 & 604 & 0.0063 & 477990 & 4026634 & 42.0 & 0.041 & 0.006 \\
\hline $40-44$ & 95296 & 897 & 0.0094 & 474238 & 3548644 & 37.2 & 0.047 & 0.009 \\
\hline $45-49$ & 94399 & 1426 & 0.0151 & 468430 & 3074406 & 32.6 & 0.056 & 0.014 \\
\hline $50-54$ & 92973 & 2280 & 0.0245 & 459165 & 2605976 & 28.0 & 0.070 & 0.023 \\
\hline $55-59$ & 90693 & 3581 & 0.0395 & 444513 & 2146811 & 23.7 & 0.093 & 0.039 \\
\hline $60-64$ & 87112 & 5512 & 0.0633 & 421782 & 1702299 & 19.5 & 0.129 & 0.067 \\
\hline $65-69$ & 81600 & 8323 & 0.1020 & 387195 & 1280517 & 15.7 & 0.184 & 0.114 \\
\hline 70-74 & 73278 & 12310 & 0.1680 & 335613 & 893322 & 12.2 & 0.267 & 0.189 \\
\hline 75-79 & 60968 & 16652 & 0.2731 & 263209 & 557709 & 9.1 & 0.390 & 0.309 \\
\hline $80-84$ & 44316 & 18952 & 0.4277 & 174198 & 294500 & 6.6 & 0.557 & 0.483 \\
\hline $85-89$ & 25364 & 15598 & 0.6150 & 87823 & 120302 & 4.7 & 0.746 & 0.694 \\
\hline $90-94$ & 9766 & 7356 & 0.7532 & 26760 & 32479 & 3.3 & 0.902 & 0.877 \\
\hline $95-99$ & 2410 & 2013 & 0.8354 & 5003 & 5718 & 2.4 & 0.976 & 0.968 \\
\hline $100+$ & 397 & 397 & 1.0000 & 716 & 716 & 1.8 & 0.996 & 0.995 \\
\hline
\end{tabular}

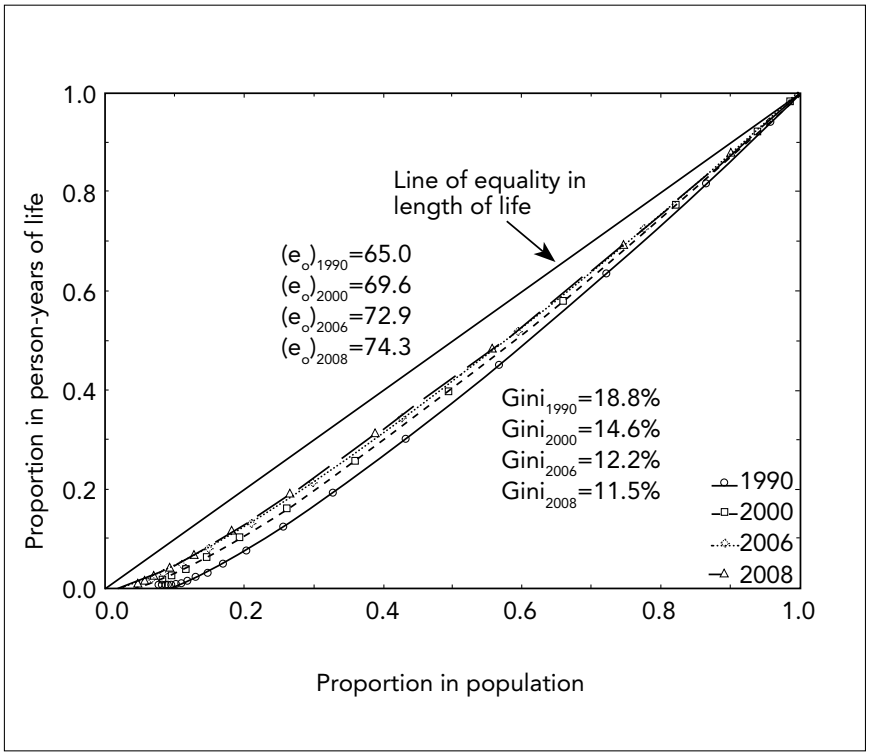

Figure 3. Lorenz Curves for Turkish population with different average levels and age distributions of mortality in different years

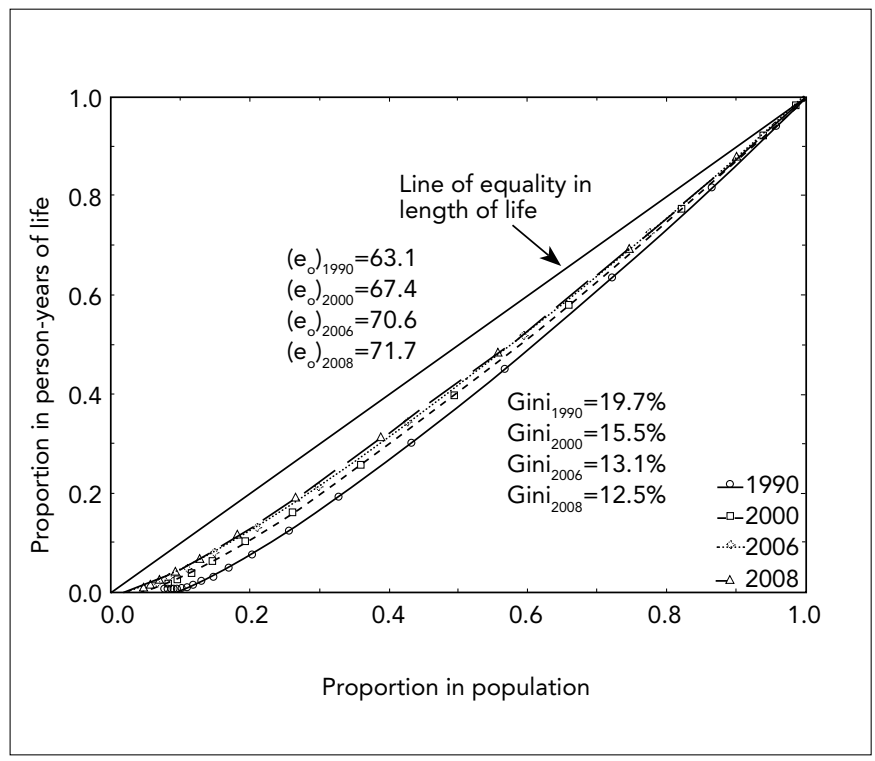

Figure 4. Lorenz Curves for Turkish Male population with different average levels and age distributions of morality in different years 


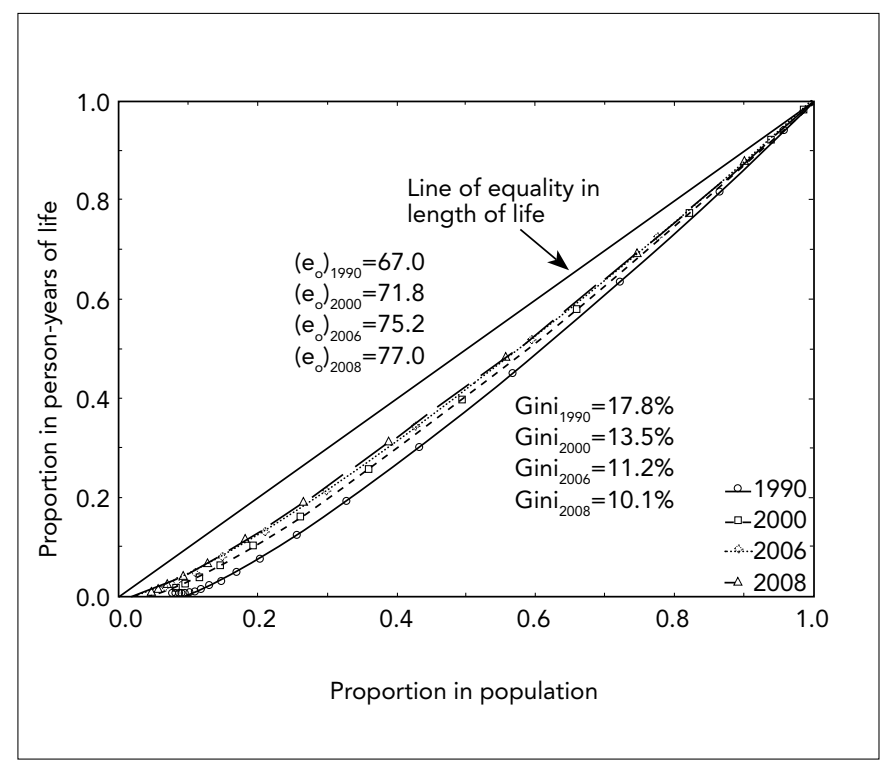

Figure 5. Lorenz Curves for Turkish Female population with different average levels and age distributions of mortality in different years

needs to be taken for that aim is to make sure that all individuals can benefit equally from available services and opportunities. Life expectancy at birth is one of the leading measures used in assessing the health level of societies and developing health policies accordingly. While average life expectancy is indeed an important and valuable measure in that sense, it does not provide information about how the length of life is homogeneously distributed among individuals. Thus, besides the life expectancy in general determined by the level of development in health, an assessment concerning how balanced its distribution is will provide more detailed information. For example, life expectancy at birth in Japan is 79.1 and extent of inequality is 0.095 in 1990 . While Turkey could only reach in 2008 the extent of inequality Japan had reached in 1990; average life expectancy in Turkey is still below that of Japan. Although our finding showed that the level of inequality among individuals is decreasing over time, the level of inequality is not as low as the level of inequality in developed countries.
The concept of inequality has frequently been used in the field of economics and social sciences in our country so far. There has not been not enough study about inequality in the health sciences. This is the first study on the evaluation of inequality among individuals in terms of life expectancy in Turkey. The level of success in ensuring individuals longer and more or less equal years of life can be judged by life expectancy and measuring disparities in life expectancy. We therefore recommend the use of Gini coefficient along with life expectancy as an important health level indicator.

\section{Conflict of Interest}

No conflict of interest was declared by the authors.

\section{References}

1. Life tables for WHO Member States. Available at http://www. who.int/healthinfo/statistics/mortality_life_tables/en/ (last visit: August 2010).

2. Özdemir P, Karabulut E. II ve Bölgelere Göre Bebek Ölüm Hızlarındaki Değişkenliğin Gini Eşitsizlik Ölçüsü ile İncelenmesi: Sağlık Alanındaki Eşitsizliklerin Değerlendirmesi. Turkiye Klinikleri J Biostat 2009;1:45-53.

3. Shkolnikov VM, Andreev EE, Begun ZA. Gini Coefficient as a life table function: computation from discrete data, decomposition of differences and empirical examples. Demographic Research 2003;8:305-58. [CrossRef]

4. Edwards RD. Trends in World Inequality in Life Span Since 1970. NBER Working Paper No. 16088. June 2010.

5. Lee WC. Characterizing Exposure-disease Association in Human Populations Using The Lorenz Curve And Gini Index. Stat Med 1997;16;729-39. [CrossRef]

6. Lee WC. Probabilistic Analysis of Global Performances Of Diagnostic Tests: Interpreting The Lorenz Curve-Based Summary Measures. Stat Med 1999;18;455-71. [CrossRef]

7. Measuring Health Inequalities: Gini Coefficient and Concentration Index. Epidemiol Bull 2001;22:3-4.

8. Haidich A, loannidis J. The Gini coefficient as a measure for understanding accrual inequalities in multicenter clinical studies. $J$ Clin Epidemiol 2004;57:341-8. [CrossRef]

9. Hanada, K. A formula of Gini's concentration ratio and its application to life tables. Journal of Japan Statistical Society 1983;13:95-8. 